\title{
Influence of different Extraction and Fractionation Periods on Humic Acid Yield derived from Pressmud and Vermicompost
}

\author{
Shreelatha $^{1}$, S. N. Bhat ${ }^{1 *}$, S. R. Balanagoudar ${ }^{1}$, R. V. Beladhadi ${ }^{1}$, \\ Satyanarayana Rao ${ }^{2}$ and M. V. Ravi ${ }^{1}$
}

${ }^{1}$ Department of Soil Science and Agriculture Chemistry, ${ }^{2}$ Department of Agronomy, University of Agricultural Sciences, Raichur- 584 104(Karnataka), India

*Corresponding author

\section{A B S T R A C T}

Keywords

Humic acid,

Pressmud,

Vermicompost,

Extraction and

fractionation period

Article Info

Accepted:

22 December 2019

Available Online:

20 January 2020
Humic acids (HA) are widely used in agriculture because of their capability as chelator, organic matter, and soil improver and growth promoter. However, their isolation differs in terms of origin or source because of wetting and solubilisation factors. This study was conducted to determine extraction period for HA from organic sources. Standard procedures were used to extract HA from pressmud (PM) and vermicompost (VC) at different extraction periods of $4,8,12,16,20$ and 24 hours and fractionation periods $(3,6,9,12,15,18,21 \& 24 \mathrm{hrs})$. At the end of each extraction period, samples were centrifuged, followed by fractionation and purification. HA yield at different extraction periods was determined using standard procedures. The relationship between extraction period and HA yield was quadratic. Extraction and fraction period for PM \& VC was 24 hours and purification (done in $1 \mathrm{~h}$ ) using distilled water was effective in removing impurities. HA from PM and VC can be extracted and fractionated in 24 hours and purification can be done in one hour.

\section{Introduction}

Humic substances are extremely versatile and critical components of the natural soil ecosystem, where they have persisted for hundreds of years .They are the most widely distributed organic products of biosynthesis on the surface of the earth, exceeding the amount of organic carbon contained in all living organisms. They provide a concentrated and economical form of organic matter that can replace humus depletion caused by conventional fertilization methods in soil. The addition of humic substances to soils can stimulate plant growth beyond the effects of mineral nutrients alone. Humic substances are extensively used all over the world due to their benefits in agricultural 
soils, especially in soils with low organic matter. They form an integral part of the ecosystem as they play an important role in global cycling of nutrients and carbon.

Humic acids can be isolated from various natural sources including organic manures and waste product of industry. But isolation period of HA differs in terms of parent material or source. For instance, extraction of HA from tropical peat (Hemist) is different from that of Saprist (Kasim et al., 2007). A study by Ahmed et al., (2005) found HA extraction period for composted pineapple leaves to be 17 hours. The HA in some compost have been in extracted 12 hours using the method of the International Humic Substance Society (Schnitzer and Skinner, 1982). Keeping these points in view, a study was initiated to find out a suitable extraction and fractionation periods to isolate HA from pressmud and vermicompost.

\section{Materials and Methods}

The HA extraction from pressmud or vermicompost was conducted in Organic Farming Research Institute, MARS, Raichur during 2018-19 using the procedures described by Stevenson (1994). This experiment was conducted in two factorial CRD with three replications. Factor A is the different extraction periods and factor $\mathrm{B}$ is different fractionation periods. Twenty grams of air-dried compost was placed into a $250 \mathrm{ml}$ polyethylene centrifuge bottle and $200 \mathrm{ml}$ of $0.1 \mathrm{M} \mathrm{KOH}$ solution was added. The bottle was stopped with its cap and the mixture was shaken at room temperature (approximately $25^{\circ} \mathrm{C}$ ) using an orbital shaker at $125 \mathrm{rpm}$ with different shaking (extraction) periods. The extraction periods used in this study were 4, 8, 12, 16, 20 and 24 hours. At the end of each extraction period, the samples were centrifuged at 2,000 rpm for $15 \mathrm{~min}$. The dark-coloured supernatant liquid was decanted; the $\mathrm{pH}$ of the solution was adjusted to 2.0 using $6 \mathrm{M} \mathrm{HCl}$ and left at room temperature for different fractionation periods (3, 6,9,12,16,19,21 \& $24 \mathrm{hrs})$. At the end of each fractionation period, the suspension was transferred into polyethylene centrifuge tube and centrifuged at 2,000 rpm for $15 \mathrm{~min}$. The liquid part (fulvic acid) was decanted. The precipitated material (HA) was purified as described in previous paper. After the purification, the HA obtained at different extraction and fractionation period was ovendried at $40^{\circ} \mathrm{C}$ until constant weight was attained, weighed and HA yield was expressed as percentage by weight. The concentration of HA was determined using Spectrophotometer at $450 \mathrm{~nm}$. The content HA was found out by dry combustion method (Hesse, 2004).

\section{Results and Discussion}

Influence of different extraction and fractionation periods on humic acid (HA) yield derived from pressmud and vermicompost are presented in Table 1 and 2.

Effect of extraction period on HA yield derived from pressmud and vermicompost

HA yield obtained with pressmud and vermicompost at different extraction period differed significantly. The 24 hours of extraction with alkali solution recorded significantly higher HA yield from pressmud ( PM) and vermicompost ( VC) (8.53 \& 6.64 $\%)$ and was significantly superior to rest of the extraction period. As the extraction period increased the quantity of HA obtained from PM or VC was also increased (Table 1, 2 \& Fig. 1,2). This could be attributed to the fact that the exchange process between $\mathrm{K}$ from the extractant and the exchange sites which consist of hydroxylic, phenolic and carboxylic functional groups of compost progressed with extraction period until a maximum period 
where maximum number of exchange sites might have been saturated with $\mathrm{K}$ ions. This extraction process might have made the sample highly soluble. These results are in line with findings of Palanivell et al,. (2012).

Table.1 Effect of different extraction and fractionation periods on humic acid yield from pressmud

\begin{tabular}{|c|l|l|l|l|l|l|l|l|l|}
\hline \multicolumn{10}{|c|}{ Humic acid yield (\%) } \\
\hline Extraction period & $\mathbf{F}_{\mathbf{3}}$ & $\mathbf{F}_{\mathbf{6}}$ & $\mathbf{F}_{\mathbf{9}}$ & $\mathbf{F}_{\mathbf{1 2}}$ & $\mathbf{F}_{\mathbf{1 5}}$ & $\mathbf{F}_{\mathbf{1 8}}$ & $\mathbf{F}_{\mathbf{2 1}}$ & $\mathbf{F 2 4}$ & Mean \\
\hline $\mathbf{E}_{\mathbf{4}}$ & 0.62 & 0.88 & 0.92 & 1.34 & 1.52 & 1.82 & 2.74 & 4.23 & 1.76 \\
\hline $\mathbf{E}_{\mathbf{8}}$ & 1.66 & 1.99 & 2.72 & 3.68 & 2.87 & 4.7 & 4.36 & 4.68 & 3.33 \\
\hline $\mathbf{E}_{\mathbf{1 2}}$ & 2.46 & 3.36 & 3.38 & 3.92 & 4.43 & 4.73 & 5.92 & 6.50 & 4.40 \\
\hline $\mathbf{E}_{\mathbf{1 6}}$ & 2.43 & 3.03 & 3.98 & 4.18 & 4.97 & 5.37 & 5.87 & 6.85 & 4.60 \\
\hline $\mathbf{E}_{\mathbf{2 0}}$ & 4.65 & 5.59 & 5.91 & 6.13 & 6.72 & 6.95 & 7.36 & 10.31 & 6.81 \\
\hline $\mathbf{E}_{\mathbf{2 4}}$ & 5.65 & 5.75 & 6.15 & 7.10 & 8.57 & 10.17 & 12.30 & 13.58 & 8.53 \\
\hline Mean & 2.87 & 3.43 & 3.84 & 4.39 & 4.85 & 5.62 & 6.42 & 7.69 & \\
\hline
\end{tabular}

\begin{tabular}{|l|c|c|}
\hline Factors & C.D (0.05) & S. Em. \pm \\
\hline Factor $(\mathbf{E})$ & 0.35 & 0.12 \\
\hline Factor $(\mathbf{F})$ & 0.40 & 0.14 \\
\hline Factor $($ EXF $)$ & 0.99 & 0.35 \\
\hline
\end{tabular}

E: Different extraction periods $(4,8,12,16,20$ and 24 hours)

F: Different fractionation period $(3,6,9,12,15,18,21$ and 24 hours)

Table.2 Effect of different extraction and fractionation periods on humic acid yield from Vermicompost

\begin{tabular}{|c|c|c|c|c|c|c|c|c|c|}
\hline \multicolumn{10}{|c|}{ Humic acid yield (\%) } \\
\hline $\begin{array}{c}\text { Extraction } \\
\text { period }\end{array}$ & $\mathbf{F}_{\mathbf{3}}$ & $\mathbf{F}_{\mathbf{6}}$ & $\mathbf{F}_{\mathbf{9}}$ & $\mathbf{F}_{\mathbf{1 2}}$ & $\mathbf{F}_{\mathbf{1 5}}$ & $\mathbf{F}_{\mathbf{1 8}}$ & $\mathbf{F}_{\mathbf{2 1}}$ & $\mathbf{F}_{\mathbf{2 4}}$ & Mean \\
\hline $\mathbf{E}_{\mathbf{4}}$ & 0.57 & 0.63 & 1.23 & 1.98 & 1.99 & 2.35 & 2.88 & 4.20 & 1.97 \\
\hline $\mathbf{E}_{\mathbf{8}}$ & 1.08 & 1.79 & 1.94 & 2.4 & 2.65 & 3.65 & 3.93 & 4.63 & 2.75 \\
\hline $\mathbf{E}_{\mathbf{1 2}}$ & 2.14 & 2.65 & 2.79 & 3.19 & 3.85 & 3.99 & 4.25 & 4.98 & 3.48 \\
\hline $\mathbf{E}_{\mathbf{1 6}}$ & 2.50 & 2.58 & 3.35 & 3.68 & 3.85 & 4.48 & 4.52 & 8.50 & 4.18 \\
\hline $\mathbf{E}_{\mathbf{2 0}}$ & 4.01 & 4.63 & 4.55 & 4.68 & 4.93 & 4.93 & 6.35 & 7.00 & 5.16 \\
\hline $\mathbf{E}_{\mathbf{2 4}}$ & 4.27 & 4.62 & 4.75 & 6.88 & 6.28 & 7.56 & 8.60 & 10.13 & 6.64 \\
\hline Mean & 2.46 & 2.82 & 3.10 & 3.80 & 3.93 & 4.49 & 5.09 & 6.57 & \\
\hline
\end{tabular}

\begin{tabular}{|l|c|c|}
\hline Factors & C.D $(\mathbf{0 . 0 5})$ & S. Em. \pm \\
\hline Factor $(\mathbf{E})$ & 0.153 & 0.054 \\
\hline Factor $(\mathbf{F})$ & 0.176 & 0.063 \\
\hline Factor $(\mathbf{E X F})$ & 0.432 & 0.154 \\
\hline
\end{tabular}

E: Different extraction periods (4, 8, 12, 16, 20 and 24 hours)

F: Different fractionation periods (3, 6, 9, 12, 15, 18, 21 and 24 hours) 
Fig.1 Relationship of extraction period on humic acid yield from pressmud and vermicompost

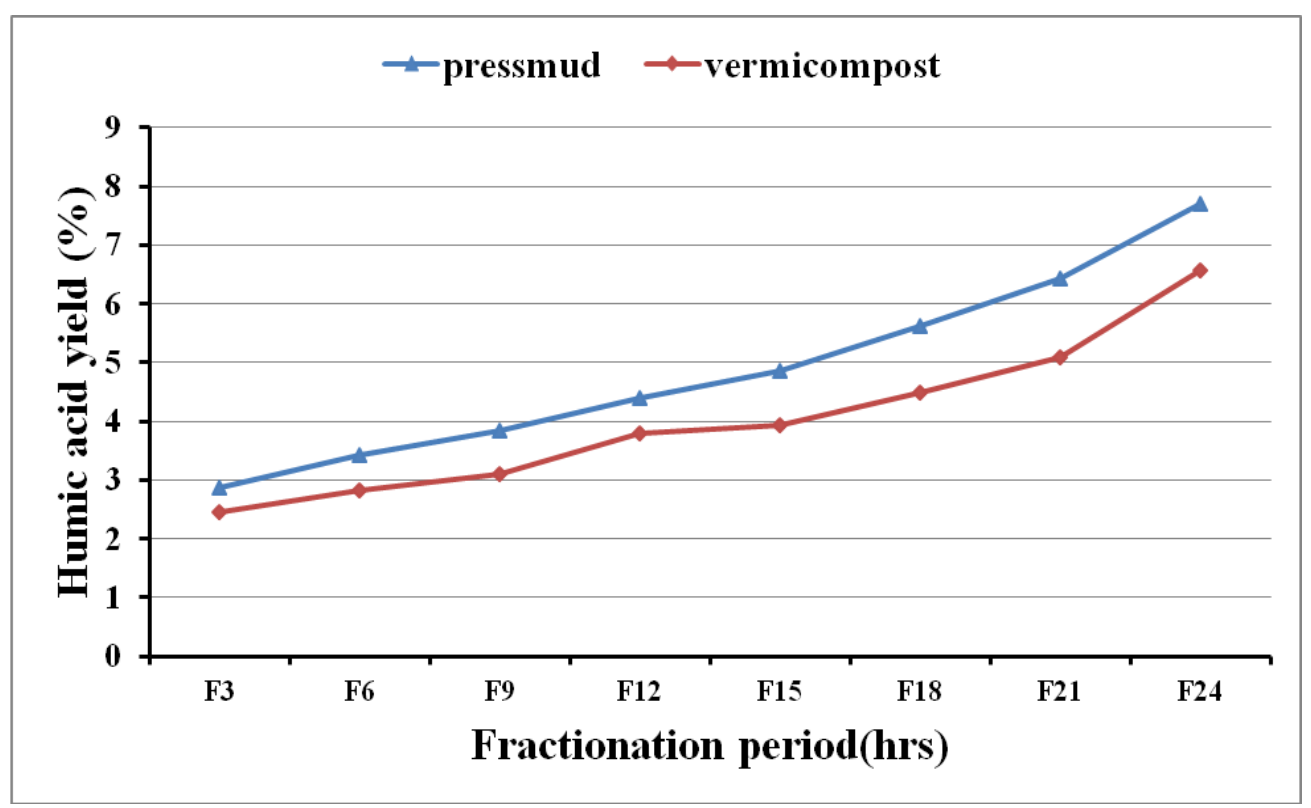

Fig.2 Relationship of fractionation period on humic acid yield from pressmud and vermicompost

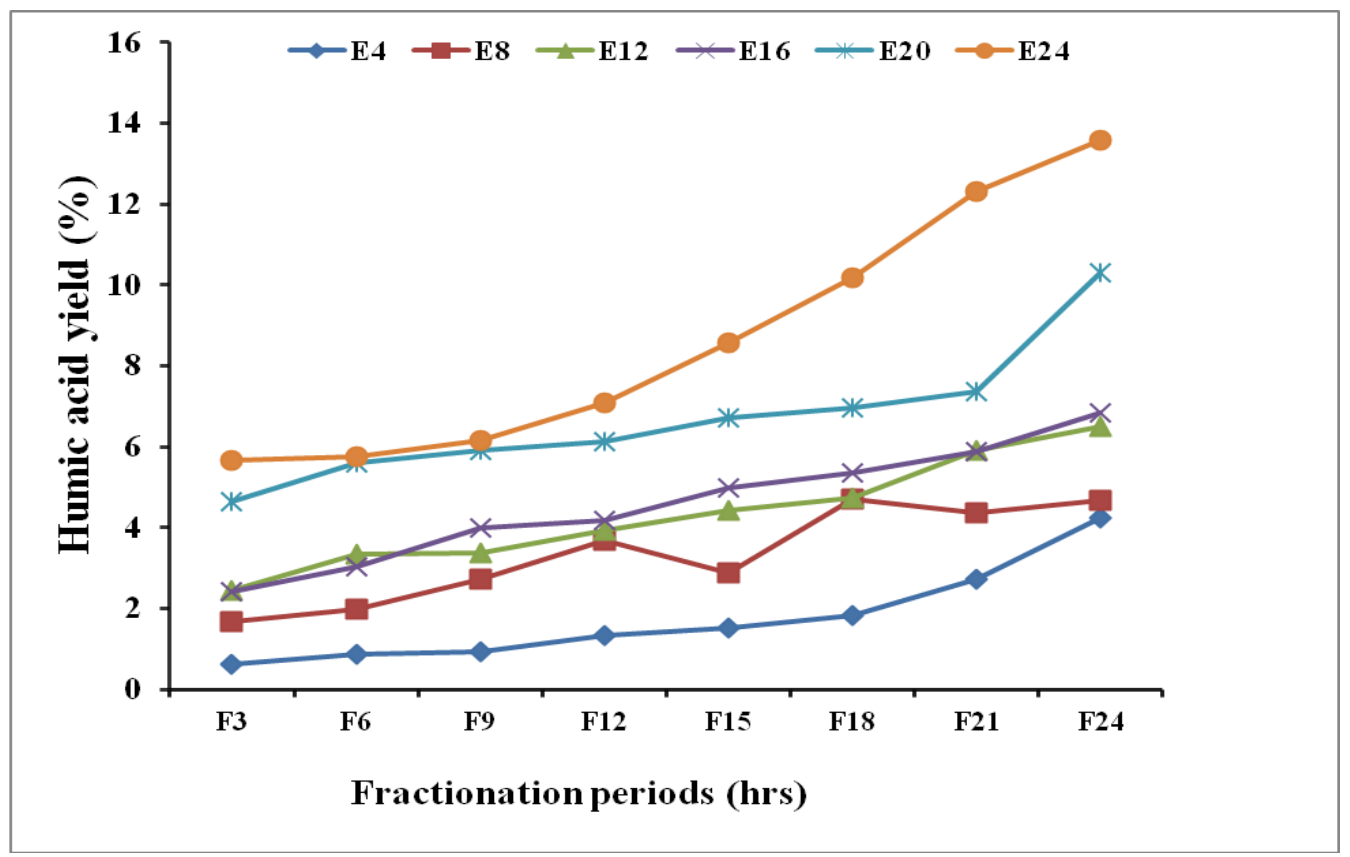


Fig.3 Interaction of extraction and fractionation periods on humic acid yield from pressmud

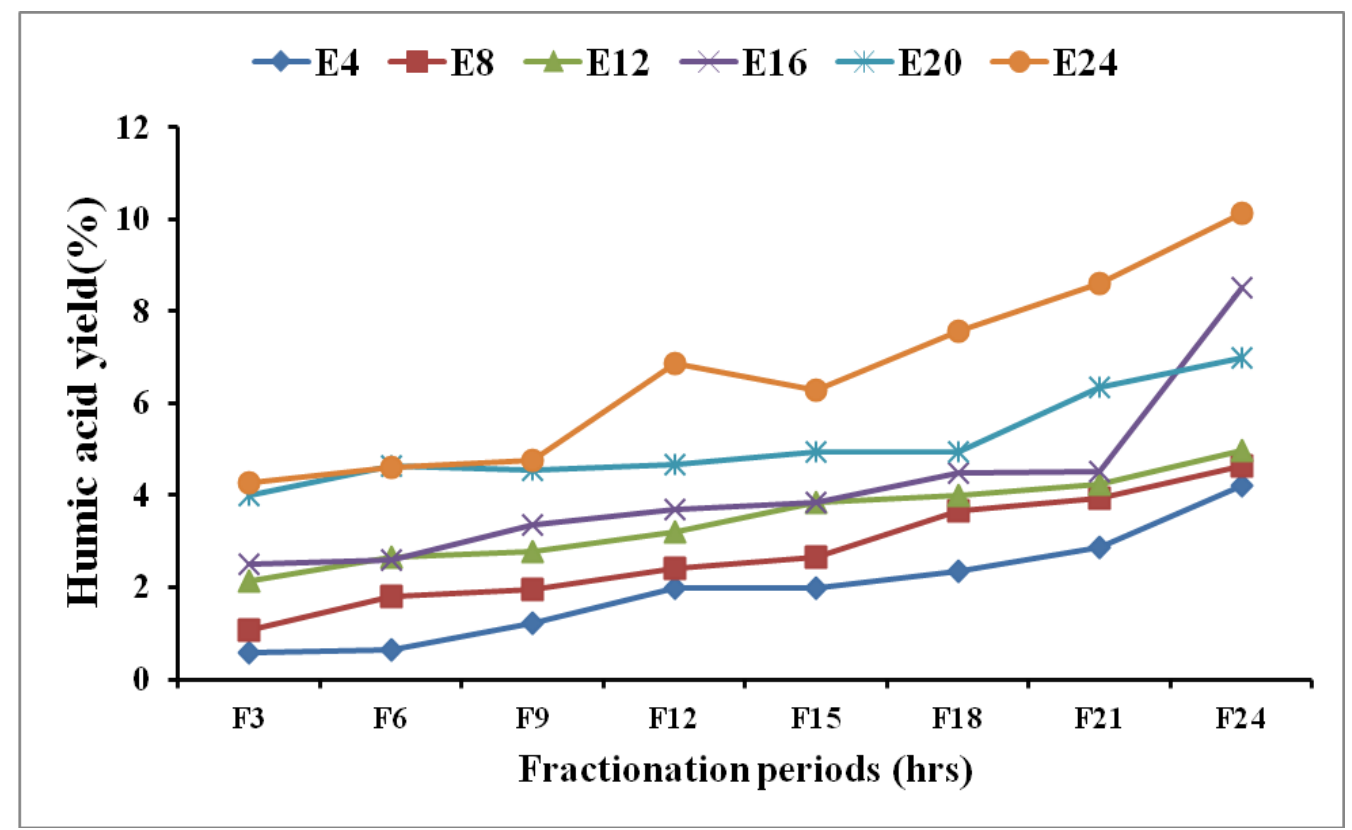

Fig.4 Interaction of extraction and fractionation periods on humic acid yield from vermicompost

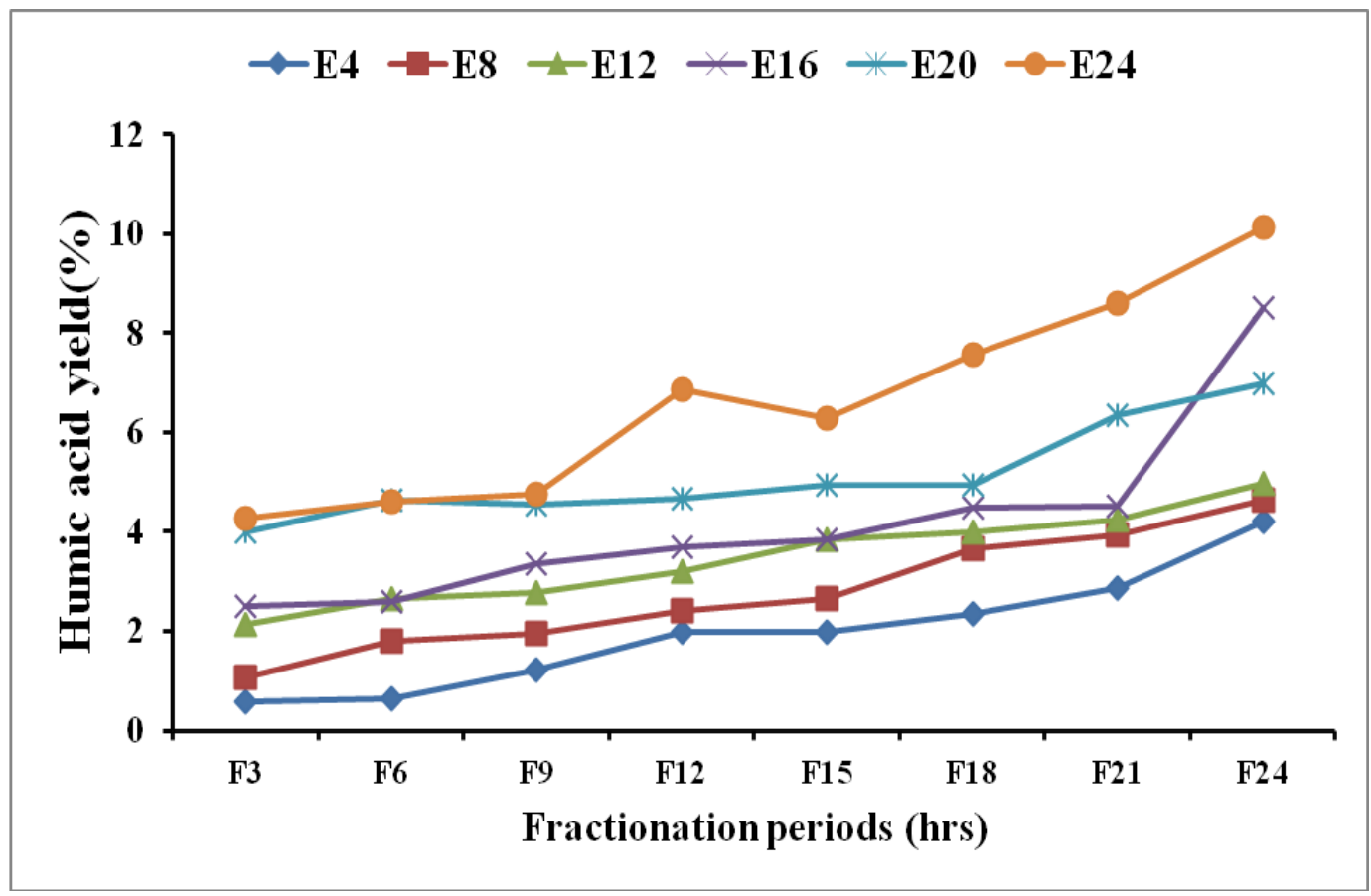




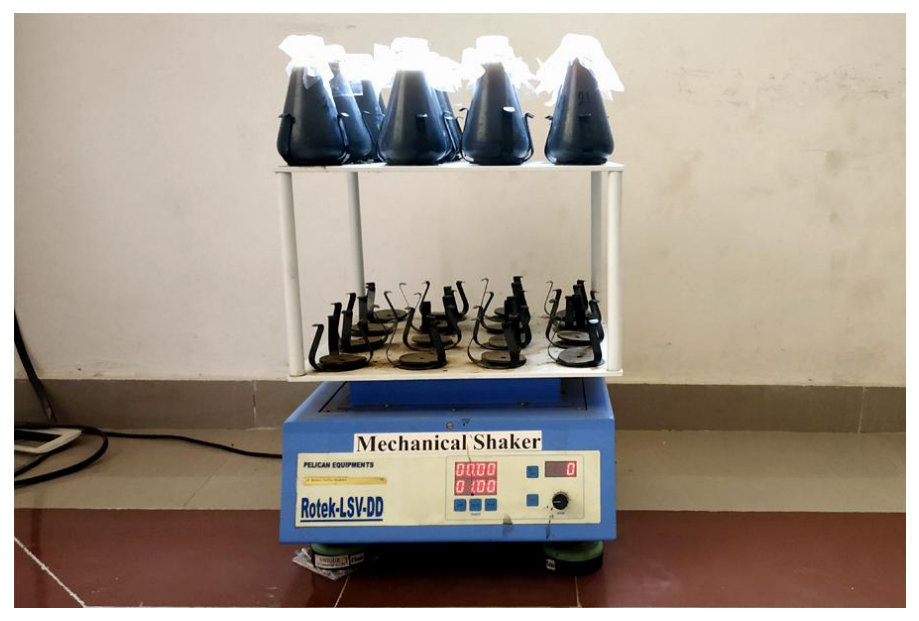

\section{Plate 1. Extraction of HA from PM \& VC}

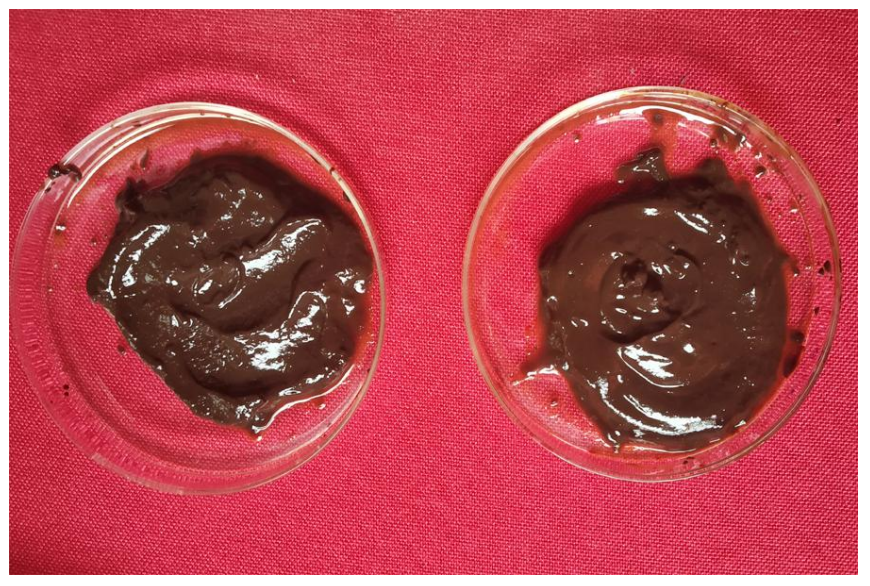

Plate 3 : Purified HA with distilled water

Effect of fractionation period on HA yield from pressmud and vermicompost

Among the different fractionation periods, significantly higher HA yield from the press mud and vermicompost, respectively was obtained at 24 hours of fractionation period $(7.69 \& 657 \%)$ compared to rest of fractionation periods. As the fractionation period increased the yield of HA derived from PM or VC was also increased ( Table $1 \& 2$ ).

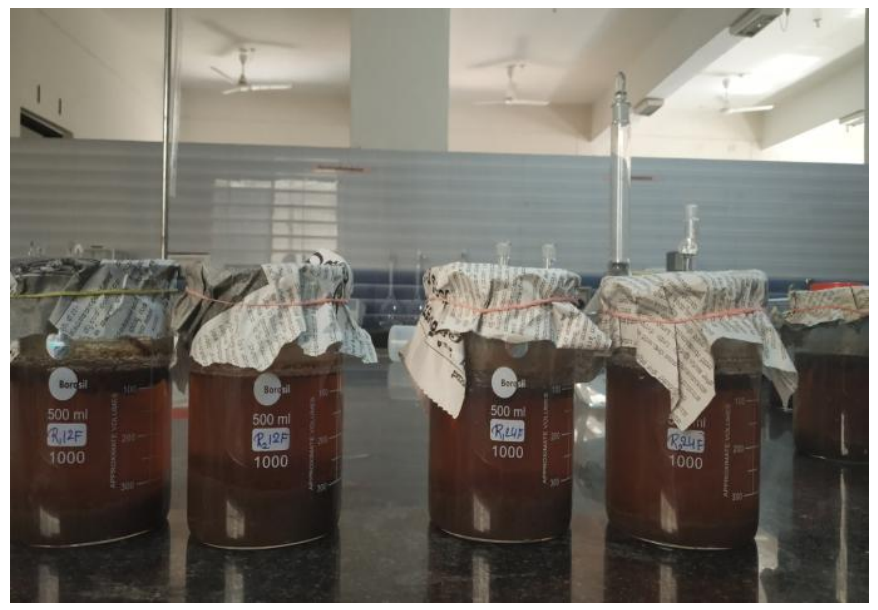

Plate 2. Fractionation of HA from PM \& VC

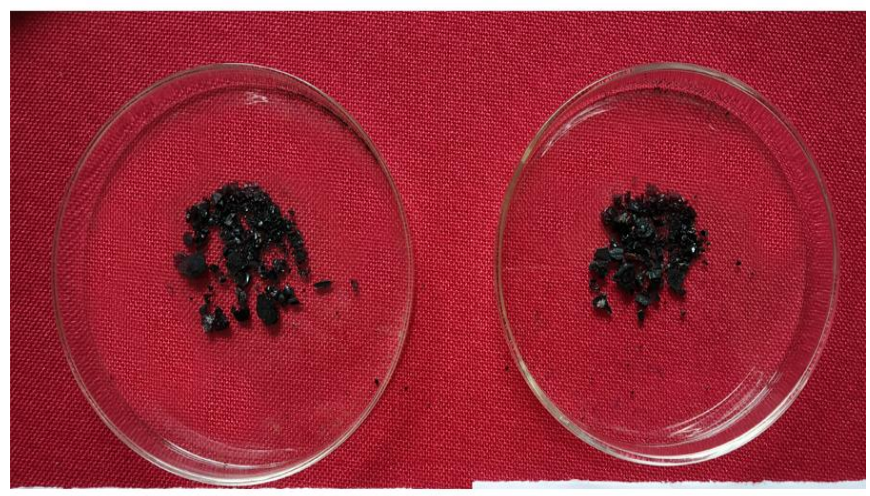

Plate 4 : HA granules

Interaction effect of extraction and fractionation period on HA yield

Among the interactions of extraction and fractionation periods, the HA yield differed significantly (Fig 3 \&4). Extraction of the pressmud and vermicompost with alkali for 24 hours and subsequent equilibration with $\mathrm{HCl}$ for 24 hours registered significantly higher HA yield of 13.58 and 10.13 per cent, respectively compared to other interaction effect. Extraction at 4 hours and fractionation 
at 3 hours recorded significantly lower $\mathrm{HA}$ yield $(0.62 \%$ in PM \& $0.58 \%$ in VC). From the foregoing results, it is evident that longer the contact time of material with alkali solution and higher equilibration period with $\mathrm{HCl}$ solution generated higher $\mathrm{HA}$ yield. The results were agreement with findings of Palanivell et al., (2012) who reported that among the different extraction periods, the maximum and optimum extraction periods of HA from rice straw compost were at 24 and 21.6 hours with 10.67 and 10.65 per cent HA, respectively.

From the above results it is clear that HA yield from both pressmud and vermicompost progressed with increasing extraction period. And higher HA yield was occurred at 24 hours of extraction. It is due to first, slowing down of depolymerisation of high molecular weight complex and secondly, exchange of $\mathrm{K}$ ions at exchange site of humic substances continued up to 24 hours of extraction period, where most of exchangeable sites of humic acid have been saturated with $\mathrm{K}$ ions making the material more soluble. Hence it generated more HA yield at 24 hours of extraction period. The lower yield obtained from pressmud and vermicompost at shorter periods of extraction is because of difficulty in wetting of organic materials with alkali solution.

In conclusion, the 24 hours of extraction with $\mathrm{KOH}(0.5 \mathrm{M})$ and 24 hours equilibration with $6 \mathrm{M} \mathrm{HCl}$ is found to be ideal to attain higher HA yield from pressmud (13.5\%) and vermicompost $(10.1 \%)$.

\section{References}

Hesse, P. R., 1994, A textbook of soil chemical analysis. Hans publication pp:111

Kasim, S., Ahmed, O. H., Ab. Majid, N. M., Yusop, M. K. and Jalloh, M. B., 2009, Reduction of ammonia loss by mixing urea with liquid humic and fulvic acids isolated from tropical peat soil. Am. J. Agric. Biol. Sci., 4(1): 18-23.

Palanivell, P., Susilawati, K., Ahmed, O. H., and Muhamad, A. N. (2012). Effects of extraction period on yield of rice straw compost humic acids. African Journal of Biotechnology, 11(20), 4530-4536.

Schnitzer, M. and Skinner S.I.M., 1968, Alkali versus acid extraction of soil organic matter, Soil Sci., 105:392-396.

\section{How to cite this article:}

Shreelatha, S. N. Bhat, S. R. Balanagoudar, R. V. Beladhadi, Satyanarayana Rao and Ravi, M. V. 2020. Influence of different Extraction and Fractionation Periods on Humic Acid Yield derived from Pressmud and Vermicompost. Int.J.Curr.Microbiol.App.Sci. 9(01): 2299-2305. doi: https://doi.org/10.20546/ijcmas.2020.901.261 